\title{
INFORMATIONAL SPACE AND ITS SUBJECTIVE BASIS
}

\author{
Marat P. Buzskiy \\ Volgograd State University, Volgograd, Russian Federation
}

\begin{abstract}
The article discusses the problem of determining the information space of modern society. Considering modern interpretations of this space, the author notes the widespread approach of describing the properties of this space from the information itself contesting the relationship between the past and the present, their interaction in modern society. Trying to solve the problem we consider the constant function of the social system, i.e. the formation of its specific historical integrity in the form of the universality of the subject - a special property of the system itself expressing the achieved level of social relations of society, forming goals, defining guidelines and patterns of behavior, as well as features of consciousness and ideas of people of this society. The article deals with the peculiarities of four historical forms of universality of the subject - myth, religion, activity and information, their interaction with the social system and personality (social subjects). From this point of view the author believes that the modern information space does not reveal its real subjective potential and should be considered as a formation, since the social system itself and its subject are historically only at the beginning of its existence.

The conceptual basis of the article lies in the identification of a special objective regularity - the dialectical interaction of the social system and its subject form generated by the system - a historically reproducing permanent mechanism, which, however, changes its content along with the development of society. The main function of the universality of the subject is to present or express the most common systemic quality as a kind of objective goal of society and at the same time to determine the main direction and nature of socio-spiritual and practical interactions of people in a particular historical era. Thus this subject acts as a special intermediary between specific individuals and the social system. It expresses some general quality of system structures or orders arising in different epochs objectively arising in society. Therefore, the information society and its space are not autonomous in relation to the past, but express the modern stage of this process - the formation of objective conditions of the system stability on the basis of accelerating dynamics of information processes and interactions. And the basis of these conditions, their concentrated manifestation is the universality of the subject in its information "objectification".
\end{abstract}

Key words: universality of the subject, the system of society, myth, religion, activity, information space.

УДК 1:004

ББК 87.526 .2

\section{ИНФОРМАЦИОННОЕ ПРОСТРАНСТВО И ЕГО СУБЬЕКТНАЯ ОСНОВА}

\author{
Марат Павлович Бузский \\ Волгоградский государственный университет, г. Волгоград, Российская Федерация
}

\begin{abstract}
Аннотация. В статье обсуждается проблема детерминации информационного пространства современного общества. Рассматривая современные трактовки этого пространства, автор отмечает повсеместно 을 распространенный подход описания свойств этого пространства из самой информации, что ставит под воп궁 рос саму связь прошлого и настоящего, их взаимодействие в современном обществе. В качестве решения ‡. проблемы рассматривается постоянная функция общественной системы - формирование своей конкретноисторической целостности в виде всеобщности субъекта, - особого свойства самой системы, которое выражает достигнутый уровень социальных связей общества, формирует цели, определяет ориентиры и схемы поведения, а также особенности сознания и представлений людей данного общества. В статье рассматриваются особенности четырех исторических форм всеобщности субъекта - мифа, религии, деятельности и () информации, их взаимодействие с общественной системой и личностью (социальными субъектами). С этих
\end{abstract}


позиций автор считает, что современное информационное пространство не раскрывает своего реального субъектного потенциала и должно рассматриваться как становление, так как сама общественная система и ее субъект оказываются исторически лишь в начале своего существования.

Концептуальной основой статьи является выявление особой объективной закономерности - диалектического взаимодействия общественной системы и ее субъектной формы, порождаемой системой, - исторически воспроизводящийся постоянный механизм, который, однако, меняет свое содержание вместе с развитием общества. Основная функция всеобщности субъекта - представить или выразить наиболее общее системное качество как некую объективную цель общества и вместе с тем - определить основную направленность и характер социально-духовных и практических взаимодействий людей в конкретную историческую эпоху. Этот субъект, таким образом, выступает особым посредником между конкретными индивидами и общественной системой. Он выражает некоторое общее качество возникающих в разные эпохи системных структур, или порядков, объективно возникающих в обществе. Поэтому информационное общество и его пространство - не автономны по отношению к прошлому, а выражают современный этап этого процесса формирование системой объективных условий своей устойчивости на основе ускоряющейся динамики информационных процессов и взаимодействий. И основой этих условий, их концентрированным проявлением является всеобщность субъекта в ее информационной «объективации».

Ключевые слова: всеобщность субъекта, система общества, миф, религия, деятельность, информационное пространство.

Все стремительные изменения, которые происходят сегодня в мире, так или иначе вызваны его информатизацией: это кажется настолько очевидным, что сама идея информационного детерминизма не требует какихлибо дополнительных аргументов. Причем речь идет не только об информационных технологиях: идея М. Кастельса, что информация структурирует общество, формируя его собственные пространство и время [Кастельс $2000,110,386]$, осмысливается как субстанциальный статус самой информации - этого гипертекста, из которого развертывается вся воспринимаемая человеком реальность его общественной жизни.

Соответственно, информационное пространство, как и время, рассматриваются как формы бытия этой реальности. Но при этом под вопросом оказываются, с одной стороны, сами особенности включения в это настоящее всего многообразного прошлого, которое проходило общество, а с другой - сферы социума и культуры, существующие в настоящем, но не сводимые к информационным потокам. Нерешенность этого вопроса, которая замещается акцентом на значимости именно настоящего, оборачивается целым рядом негативных результатов: разрастанием масштабов и роли в обществе техногенной среды, уменьшающей статус и значимость социума, значительным ограничением (а то и ликвидацией) экзистенциального бытия личности, которая адаптируется к среде компьютерных коммуникаций, общей тенденцией роста дегуманизации, социального отчуждения, кризисных явлений в социуме и др. Все это оказывается платой за необходимость извлекать наиболее своевременную, адекватную и точную информацию о самых разных явлениях, предотвращая ее быстрое устаревание. Ведь успешная деятельность может осуществляться лишь на основе релевантной информации, в которой зафиксированы события и связи, происходящие в момент настоящего или ближайшего будущего. Устаревшая информация открывает неподлинную, уже снятую реальность, работа с которой порождает риски и кризисы.

Таким образом, информационное общество постоянно скользит по «лезвию бритвы», сохраняя режим ускоряющихся изменений, огромной внутренней напряженности и постоянной «погони за уходящим временем»: остановиться или замедлить темпы - чревато отбрасыванием назад и появлением новых зависимостей. Но этот режим не позволяет даже освоить настоящее: оно ускользает раньше, чем раскрывает для людей все свои связи и потенциал. Этот феномен одним из первых раскрыл еще в XX веке Э. Тоффлер: ускорение времени порождает у людей шок и болезни из-за их неспособности адаптироваться к темпам происходящих перемен [Тоффлер 2001, 560].

Какие же трактовки информационного пространства предлагаются и обсуждаются в современной философской литературе? 
Прежде всего, на первый план выходит идея о самодостаточности информационного пространства, выступающего как совокупность каналов коммуникации. В.С. Игнатов и Д.В. Пименова считают, что «в информационном пространстве происходят процессы, имеющие определяющее значение для развития цивилизации: формируются и циркулируют научные представления, продуцируются и распространяются технологии, фиксируются поведенческие стандарты. Социальное пространство конфигурируется коммуникационными каналами, по которым происходит обмен информацией между его элементами» [Игнатов, Пименова 2007, 4].

$\mathrm{C}$ точки зрения данных авторов, информационное пространство определяет социальное пространство также тем, что способно формировать и изменять социальный статус субъектов, их позиции в социуме. «В качестве одной из возможных осей, вдоль которой могут быть расположены статусные позиции, утверждают В.С. Игнатов и Д.В. Пименова, может быть возможность доступа к определенным видам информации, характеристики каналов связи, по которым передается определенная информация. В этом случае информационное пространство будет непосредственно формировать стратификационные вертикали, то есть конфигурировать социальное пространство, определять его социальную структуру. Современные информационные технологии позволяют сблизить социальную дистанцию не только в личной сфере, но и в сфере бизнеса, давая возможность участвовать в деятельности мировых бирж. Любой индивид может оказаться участником торговой сделки, где в качестве его партнеров могут быть мировые лидеры экономики» [Игнатов, Пименова 2007, 7].

Исследуя современные концепции информационного пространства, А.И. Ненашев в своей диссертации «Информационное пространство современного общества: коммуникационный аспект» выделяет несколько подходов: экономический - рассматривает это пространство как ресурс экономического развития (Д. Белл, В.Л. Иноземцев, И.Я. Левяш); технологический - здесь это пространство выступает как источник и носитель новых технологий и основа внедрения научных ин- новаций в процесс социального развития (Э. Шидлер, И.С. Мелюхин, А.В. Лебедев); коммуникационный (Ю. Хабермас, М. Маклюэн); сочиокультурный, сторонники которого выявляют роль информационного пространства в процессе социальной и культурной идентификации индивида (Э. Тоффлер, П.К. Огурчиков, Е.В. Листвина). Кроме этого, отмечаются политические аспекты этого пространства: его представители (Бауман, Э. Гидденс, К. Лэш) стремятся выявить в информационном пространстве борьбу политических группировок за контроль над информацией, рассмотреть особенности информационной безопасности, информационные риски и др. [Ненашев 2008, 5].

Таким образом, хотя существует значительная литература по проблематике информационного пространства, раскрывающей его различные «срезы» и свойства, однако единой концепции этого пространства пока еще не создано. Сходство подходов существует - в установке или принципе приоритетности этого пространства в формировании экономических, социальных, культурных, политических и других отношений в современном обществе. В Заключении своего автореферата А.И. Ненашев справедливо отмечает, что «существующие концепции информационного пространства, как правило, сводят его специфику к той сфере общественной жизни, которая представляется основополагающей по своему воздействию на структуру информационных потоков» [Ненашев 2008, 20], но вместе с тем и формируется этими потоками.

Признаются также его следующие свойства этого пространства:

- оно представляет собой совокупность результатов человеческой семантической деятельности;

- включает в себя базы и банки данных, технологии и информационные коммуникационные системы, которые обеспечивают информационное взаимодействие граждан и организаций, а также удовлетворяют в определенной мере их информационные потребности.

Кроме того, данное пространство динамично, не имеет четких границ и организовано в виде информационных полей и информационных потоков. Первые представляют со- 
бой совокупность всей информации, которая сосредоточена в данном объеме пространства-времени; вторые выражают совокупность данных, которые перемещаются в данном пространстве по специальным каналам коммуникации. Здесь также выделяется виртуальная среда, в которой сосуществуют потоки коммуникаций. Таким образом, здесь существует свой собственный пространственно-временной континуум, который «оформляет» специфику и самодостаточность всей сферы информационных процессов.

Итак, информационное пространство существует как процесс становления. Это носитель тестовой информации, которая существует в режиме on-line. Важнейшая особенность информационного пространства - его самодетерминация.

Здесь и возникает важнейшее противоречие в понимании информационного пространства: существуя как динамическая реальность, в которой осуществляется становление и смена, оно вместе с тем фиксируется как устойчивая реальность, то есть как нечто ставшее, причем сам его генезис оказывается как бы «за скобками». Автор данной статьи выдвигает предположение о том, что причиной этого перманентного противоречия, которое тормозит формирование общей теории информационного пространства, является пропуск той глубинной логики развития общественной системы, которая определяется и выявляется как этапы формирования всеобщности субъекта, современный «облик» которого как целого, регулирующего общественную систему, и «объективируется» в свойствах современной глобальной информационной среды.

Всеобщность субъекта - это проявление целостности общественной системы, которая саморегулируется, координируя связи и взаимодействия различных локальных миров (государства, народы, общности и др.) на основе создания (порождения) некоторого общего отношения (или качества), которое осваивают и воспроизводят самые разные подсистемы. Именно эта функция всеобщности субъекта как целого обеспечивает устойчивость и внутреннее развитие (то есть конкретное историческое «состояние») самой общественной системы. Этот систем- ный «субъект» формируется объективно и независимо от сознания людей, что и превращает его собственное пространство в сферу развития, сосуществования и взаимодействия локальных миров. Однако его историческое формирование всегда скоординировано с уровнем развития самой общественной системы: поэтому его собственное пространство, во-первых, всегда совместимо с нормами данного конкретного общества, или эпохи. А, во-вторых, оно выступает для современников как некая цель, которая регулирует их сознание и поведение ${ }^{1}$. То есть собственное пространство этого субъекта оказывается первичным по отношению к любым местным условиям существования людей. Это осознается как некая данность, как нечто очевидное и не обосновывается специально: оно определяется и воспринимается как современность в любые исторические эпохи бытия общества.

Впервые на абстрактном философском уровне необходимость бытия такого субъекта для существования и развития реальности раскрыл Г.В. Гегель. Определяя основания реальности как «субстанцию-субъект», он писал: «Живая субстанция, далее, есть бытие, которое поистине есть субъект или, что то же самое, которое поистине есть действительное бытие лишь постольку, поскольку она есть движение самоутверждения, или поскольку она есть опосредствование становления для себя иною. Субстанция как субъект есть чистаяпростая негативность, и именно поэтому она есть раздвоение простого, или противополагающее удвоение, которое опять-таки есть негация этого равнодушного различия и его противоположности; только это восстанавливающееся равенство или рефлексия в себя самое в инобытии, а не некоторое первоначальное единство как таковое или непосредственное единство как таковое, - есть то, что истинно. Оно есть становление себя самого, круг, который предполагает в качестве своей цели и имеет началом свой конец и который действителен только через свое осуществление и свой конец» [Гегель 1992, 9].

Таким образом, именно субъект определяет движение, или изменения, субстанции. Этот субъект, согласно Гегелю, является средством или источником порождения пред- 
метности, то есть существования предметов для человека. «Лишь духовное есть то, что действительно; оно есть сущность или всебе-сущее, оно есть то, что вступает в отношения, и то, что определено... оно должно быть знанием о духовном и знанием о себе как о духе, это значит, оно должно быть для себя в качестве предмета, но столь же непосредственно в качестве предмета снятого, рефлектированного в себя. Предмет для себя есть лишь для нас, поскольку его духовное содержание порождено им самим» [Гегель 1992, 18]. Здесь как раз основной является идея о том, что субъект конституирует реальность: она - его «объективация».

Сохраняя идею «объективации» как проявление всеобщности субъекта (хотя и исходя из иной трактовки самой всеобщности субъекта, чем у Гегеля), мы должны теперь показать, почему на современном этапе развития общества такой «объективацией субъекта» с необходимостью становится информация.

Вернемся к понятию «всеобщность субъекта». Почему целое общественной системы является именно субъектом, а не определенным текстовым или символическим кодом, неким устойчивым системным порядком - структурой? Причина здесь в том, что само существование общества как системы держится на тех понятийно-символических связях и действиях, которые осуществляют люди. Переводя свои потребности и интересы в язык, в знаково-символические формы, индивиды и общности создают некую интерсубъективную среду - реальность, которая принципиально сама не становится объектом. Именно сквозь призму этой среды, объективной для индивидов и исторически меняющейся, для них начинает существовать и сам предметный мир, и их собственное отношение к нему.

Х.-Г. Гадамер пишет: «Человек, живущий в мире. не просто снабжен языком как некоторой оснасткой - но на языке основано и в нем выражается то, что для человека вообще есть мир. Для человека мир есть “тут” в качестве мира; ни для какого другого живущего в мире существа мир не обладает подобным тут-бытием Однако это тут-бытие мира есть бытие языковое... Иметь мир - зна- чит иметь отношение к миру. Но отношение к миру требует такой свободы от того, что встречается нам в мире, которая позволяла бы нам ставить это встречающееся перед собою таким, какого оно есть. Эта возможность пред-ставления означает одновременно обладание миром и обладание языком» [Гадамер 1988, 512-513].

Таким образом, символическая интерсубъективная среда выполняет функцию субъекта, поскольку она формирует адекватное индивиду пространство его активности и свободы, его способности понимать других и общаться с ними, определять реальность, принимать решения и т. п. Но эта среда, во-первых, оказывается объективной для индивидов - они находят себя в ней как «исходный пункт» их существования в обществе и в мире; во-вторых, она позволяет выстраивать индивидуальные и групповые отношения к вещам, то есть осваивать их на основе тех схем деятельности, смыслов, целей и технологий, которыми они исторически располагают. Но историческое развитие общества предполагает и изменение «кода» этой интерсубъективности, то есть тех форм и смыслов, в которых она существует, и открывает для людей новые возможности в освоении окружающей природной и социальной среды. Это изменение всеобщности субъекта (интерсубъекивности) необходимо для сохранения самой общественной системы и выполнения всех его основных функиий по отношению $к$ этой системе, и в первую очередь - регулятивно-смысловой. Какие же формы, или воплощения, приобретала всеобщность субъекта в развитии общества?

Предварительно отметим, что всеобщность субъекта - «выражает всеобщую интенциональность» (точнее - является ее коллективным источником) и «заполнена» различными символическими, нормативными и другими реальностями, формами, текстами и свернутыми в информационные воплощения схемами поведения. Она выражает целостность общества по отношению к индивидам, то есть не только воспринимается их сознанием, но и переживается через их включенность в это пространство, которое, в конечном итоге, создали сами. Всеобщность субъекта - это выведенная на уровень обще- 
ства собственная коллективная свобода индивидов, оторвавшаяся от них в своем бытии, но сохранившая (в себе) все мотивационные и побуждающие к действию элементы. Она существует в виде некоторой внутренней социально-символической формы, выражающей свою регулятивную сущность в управлении свободой (то есть поведением, ориентацией) индивидов. Создавая цели, ценности, идеалы, другие образы будущего и должного, всеобщность субъекта открывает (формирует) то общее, к которому движутся люди в своих действиях и интересах» [Бузский 2002, 52].

Уточним, что понятие «свобода» в пространстве всеобщности субъекта выражает его собственное историческое развитие: если в первобытном обществе свобода существует в рамках родовой общности (этносов), а в Средние века - в сословно-корпоративных пределах (хотя уже открыта духовная свобода верующего как его отношение к Богу), то индивидуальная свобода возникает лишь в Новое время. Но в любых своих вариантах свобода здесь выражает тот потенциал, который возникает и существует у людей конкретной исторической эпохи, - накопленные ими технологические и культурные формы своего существования.

Подчеркнем, что всеобщность субъекта - это базовое общесистемное качество, которое возникает объективно - через усложнение и развитие системы, определяя период ее собственной устойчивости и внутреннего порядка (структуры). Поэтому связь всеобщего субъекта и индивида существует через системное опосредование. «Для всеобщности субъекта характерно не прямое воздействие на объект, а создание некоторого порядка, условий, в которых как действуют сами индивиды, так и развертываются общественные отношения, связи. Всеобщность субъекта - это создание коллективной меры, охватывающей свободу и активность индивидов, а потому обеспечивающей... [любым] субъектам возможность осуществлять свои собственные функции» [Бузский 2002, 53].

И здесь необходимо сделать важное для нас пояснение. Всеобщность субъекта не является той формой, к которой адаптируется социальная система. Наоборот, этот субъект выступает как особая функция самой си- стемы, определяющая режим ее устойчивости в определенный период исторического времени. Система, которая выходит за рамки данного субъекта, как бы становится для него «сложной», создает через свои собственные возникающие ресурсы и ведущие отношения новую форму всеобщности субъекта, в которой восстанавливается устойчивость общественной системы на новом этапе.

Эта диалектика напоминает известный закон соответствия производственных отношений уровню и характеру развития производительных сил. Так же, как последние в своем собственном развитии меняют форму производственных отношений, так и система в своем объективном изменении (рост населения, развитие и усложнение структур, разделение труда, возрастание внешних связей и др.) как бы «подбирает» необходимую для нее форму целостности - форму всеобщности субъекта. Тем самым сохраняется базовое общественное свойство - постоянство субъектно-объективного взаимодействия как условие существования самого общества на основе активности его субъектной стороны. «Облик» всеобщности субъекта - это выделенный или достигнутый уровень самой системы, который способен поднять социальные связи людей до уровня или особенностей организации, в которых может быть выражена их всеобщность на данном историческом этапе.

Таким образом, взаимодействие "система - субъект» является одним из наиболее фундаментальных онтологических свойств общества: это - базовая детерминанта, которая определяет общие характеристики и «лицо» каждой крупной исторической эпохи. При этом данное взаимодействие является особой константой, или постояннымм свойством общества. Поэтому рост, развитие системы меняет «облик» всеобщности субъекта, как и свое содержание, но не может прервать это базовое соотношение. Отсюда - непрерывность истории и ее «кумулятивная» по содержанию направленность - сохранение прошлого.

Итак, какие же основныле формы всеобщности субъекта явились в истории общества его наиболее глубинными регуляторами? Мы выделяем - как философские категории, выражающие эти формы, - миф, религию, 
деятельность, информацию. Оставляя для информационной формы субъекта больше внимания, рассмотрим остальные в самых общих чертах.

Первобытный миф - это первая форма (выражения) всеобщности, которая открывается для древнего человека. Здесь отсутствует личностное измерение, а поэтому миф легко отождествляется с реальностью. Миф - это единственная форма всеобщности субъекта, которая в своем символическом проявлении совпадает с устройством родового общества. Как замечает А.Ф. Лосев, «любое построение отвлеченной мысли, которое является только отражением действительности, для мифа является самой действительностью со всеми ее материальными и вещественными свойствами... В мифе все идеальное вполне тождественно с материальным и вещественным, а все вещественное ведет себя так, как будто бы оно было идеальным» [Лосев 1964, 458].

Это обеспечивает абсолютную включенность древнего человека в мифы своего рода или племени: здесь отношение к самому мифу принципиально отсутствует. Поэтому субъектом является «мифологизированный» род (этнос). Управление человеком в этой всеобщей форме субъекта осуществляется на уровне бессознательного: древний человек воспроизводит нормы и ритуалы своего племени как бы стихийно, они определяют его поведение и этапы жизни. «Бессознательное (в древнем обществе. -. . Б.) является инструментом с единственным значением, - отмечает К. Леви-Стросс, - оно подчиняет действительность структурным законам, которыми и исчерпывается его реальность, нерасчлененные элементы, поступающие извне: намерения, эмоции, представления, воспоминания» [ЛевиСтросс 1983, 181]. И эти структурные законы, которые воспроизводятся в жизни древних людей как связанные комплексы «бинарных оппозиций», моделируются в мифах, являясь безусловной и единственной «программой» жизнедеятельности людей в эту эпоху.

Второй исторической формой всеобщности субъекта стали мировые религии. Здесь впервые сам этот субъект в превращенной форме (Бог, Дух) как бы отделяется от общественной системы, возвышается над ней и формирует отношение к нему в виде верований, трансцендентных переживаний и т. д. «Вместе с всеобщностью Бога-субъекта и на ее основе открывается (как существенное свойство человека) и свобода личности, которая как раз направлена в глубину всеобщности субъекта - к постижению Бога и переживанию его воздействия. (Вместе этим свобода направлена и внутрь личности - как ее собственный духовный мир.) Ни одна последующая форма всеобщности субъекта не открывала с такой ясностью связь между индивидом и всеобщей субъектной формой, как религия, и прежде всего потому, что субъектная функция управления, выраженная через всеобщность субъекта, никогда столь ясно не отделялась от самого общества» как системы [Бузский 2002, 66].

Но здесь возникает интересный феномен: непосредственно представшая перед этим субъектом личность, которая «пропускает» саму общественную систему и ее опосредования, вместе с тем бесконечно дистанцируется от Бога-субъекта, который находится принципиально в «другом измерении»: сам по себе Бог непознаваем и недоступен для контактов с ним. Тем не менее этот субъект связывает индивидов уже на межнациональном уровне: верующие христиане (немец, итальянец или даже православный русский) равны друг другу в духовно-религиозном плане как лица, существующие в наднациональном пространстве Церкви.

Этот субъект регулирует поведение и мышление людей через нормы морали, задавая им смысл и цели жизни, как и объясняя место человека в мире - между сферами духовного и «тварного» уровней бытия. В то же время его доминирование выхолащивает и обесценивает реальность - природно-телесное начало, связанные с ним человеческие чувства. Поэтому не случайно, что средневековый мир в «своих основах казался неподвижным. Вечность, а не время, была определяющей категорией сознания» [Гуревич 1972, 266267]. Это - еще одно проявление «надмирового» статуса Бога-субъекта и вместе с тем особого отчуждения этой всеобщей субъектной формы от реальных людей, так как сама общественная система оказывается еще неразвитой с точки зрения своей все- 
общности - отсутствуют материально-экономические и другие связи, развитое разделение труда, объективность рыночных связей и др. Отношения между людьми здесь выражаются в личном служении вассала своему господину: эта общественная позиция также моделируется врелигиозной картиной мира.

Третьей исторической формой всеобщности субъекта стал переход общества в новый объективныи ирежим», который обозначается как субстанциализаиия феномена деятельности: именно требование развития общества, осуществляемого через технологические и организационные инновации, стало основой перехода к капиталистическим общественным отношениям, основанным на новом, расширенном способе производства. Здесь важно отметить, что сама по себе деятельность не начинается в новое время - она возникает с самого начала существования общества. Но в этот период впервые возникает философски-мировоззренческое отношение к деятельности, которая открывается для сознания и осмысления как новая форма связи между человеком и миром и которая становится основным определением человека-субъекта. Внутри пространства деятельности возникают новые регулятивные цели - рост ее производительности, приоритет (линейного) времени над пространством, резко возросшая ценность свободы, активности личности, ориентация на освоение будущего как основного ресурса необходимых изменений.

Деятельность как выражение всеобщности субъекта стала наиболее плодотворной «платформой», или условием, всестороннего постижения человека, его субъективности. Вообще функция познания реальности, которая воплощается в бурном развитии науки, распространяется и на художественную культуру, в новых жанрах которой исследуются человеческие образы и выявляются новые идеалы; она становится развитием самосознания общества, социума, что впоследствии сформировало общественные науки, рациональную политическую практику и др.

Вместе с тем, несмотря на то, что здесь человек уже входит в само пространство всеобщности субъекта - воспроизводит его ос- новные требования и специфику, дистанщия между личностью и этим субъектом не устраняется, несмотря на формирование объективности и развитой инфраструктуры самой общественной системы. Прежде всего, абстрактная безличность этого субъекта выражается в постоянном требовании экономии времени: индивиды попадают в ситуацию непрерывного «сжатия» и ускорения социального (и физического) времени, которое господствует над пространством, выражая сущность бытия и движения капитала. Далее, возникает отчуждение от самого труда, который воспринимается «как проклятье» и от которого «бегут, как от чумы» (Маркс). Появляется классовый антагонизм, обостряются разного рода социальные противоречия.

Деятельность как всеобщность субъекта оборачивается дегуманизацией, стандартизацией, обезличиванием и технизацией самой общественной системы. Ее собственные риски и неустойчивость наиболее полно выражаются в XX веке: экологический кризис, неудержимый рост населения, абсолютное разрастание овеществленной и техногенной среды, ограничивающей и уменьшающей собственное пространство человеческой субъективности - это проявления уже более глубокого отчуждения: между всеобщностью субъекта и общественной системой, между этой последней и личностью и т. п. И совсем не случайно, что именно в XX веке появляются новые способы организации общественной системы (в первую очередь социалистические), в которых возникает тенденция разрешения противоречия между личностью и системой при сохранении деятельностной основы всеобщности субъекта: гуманизация труда, идеал всесторонне развитой личности, гармонизации социальных отношений между субъектами, попытка реализации идеи (или принципа) социальной справедливости и др. Однако социализм также не дал точного ответа - может ли соответствовать принципам гуманизма и гармонизации взаимодействия личности и общества сама форма всеобщности субъекта, выраженная в приоритете деятельностного подхода.

Итак, сегодня возникла и активно утверждается четвертая историческая форма всеобщности субъекта - информатизаџия 
общества. Почему все-таки она «снимает» предшествующую форму субъекта как деятельности $^{2}$ - как ее объективную неспособность разрешить выявленные противоречия, или по каким-то другим причинам? Для ответа на данный вопрос можно выдвинуть гипотезу о том, что одним из глубинных «векторов» смены форм всеобщности субъекта является тенденция роста человеческой свободbl, которая соответствует развитию общественной системы: чем более сложной и развитой выступает эта система, тем больше свободы (инициативы, творчества) человека, личности требуется для их существования в этой системе и ее освоения. Поэтому конкретное проявление всеобщей формы выражает растущие свойства общества обеспечить эту свободу как всеобщее отношение, или фундаментальное системное качество. Повышает ли уровень свободы личности информационное общество? Если все-таки эта тенденция здесь сохраняется, то через какие фундаментальные модификации общественной системы? Как взаимосвязаны информация и свобода?

Рассмотрим теперь этот основной аспект данной статьи. Информационное общество - это современный способ самоорганизации общественной системы, которая может реально существовать и быть относительно устойчивой лишь при условии глобализации, ускорения времени, создания виртуальной планетарной связи, постоянного включения личности в информационные потоки и перевода основных общественных связей и отношений в компьютерно-цифровой вариант, то есть усилении тенденции преобладания количественных «определений» и выражений реальности над качественными. Информационное содержание системы формирует и свою всеобщность: субъектная форма выступает как носитель и источник информачионного детерминизма.

Здесь открывается и сама необходимость перехода к информации: сохранение субъектного регулирования системы, которая сама формирует такое регулирование, как основание собственной целостности, в условиях огромных темпов изменения самого общества выдвигает именно информацию, которая значительно опережает все другие ком- поненты общественной жизни: производительность труда, рост населения, рост производства и потребления энергии и др. Унаследовав от промышленной эпохи приоритет ускоряющегося времени, современная общественная система перевела это время из абстрактной объективной длительности во все более компактные и все более быстро самообновляющиеся потоки информации. Время превращается в информацию, которая структурируется информационным пространством (сетевое общество и его пространство как «разделенные потоки времени»- по М. Кастельсу).

А. Еляков видит фундаментальные признаки информационного общества в следующем: «Всякий субъект (человек, группа и т. д.) в любое время и в любом месте может получить за плату или бесплатно любую информацию по интересующему его личному или общественно значимому вопросу. В обществе производится и функционирует необходимая для работы информационная технология. Имеется развернутая инфраструктура, позволяющая создавать, поддерживать и развивать гигантский комплекс информационных ресурсов, обеспечивающая динамическое развитие общества. Она способна производить все виды информации, и в первую очередь научную. Наряду с социосферой, техносферой и т. д. создана специфическая инфосфера для развития коммуникационных сетей, информационных технологий, которые связывают любой континент или регион, а главное, мировое сообщество воедино. С быстрым ростом телекоммуникаций, компьютеров и компьютерных терминалов и значительным уменьшением стоимости компьютерных операций, стремительным увеличением сети хранилищ, банков данных проблема синтезирования различных средств, методов и путей передачи информации в глобальном масштабе приобретает реальный характер. Формируется единое мировое информационное пространство (курсив мой. - М. Б.). Происходит интенсивная концентрация теоретического знания, оно становится основой изменений в производстве, а в конечном итоге - в обществе» [Еляков 2001, 79].

Таким образом, здесь весьма характерным является абсолютный рост структуры, расширение пространства, ускорение событий 
в самом пространстве. Касаясь проблемы свободы человека, автор отмечает: «В этом обществе человеческая свобода предстает по-иному. Напомню наиболее известное изречение: свобода - осознанная необходимость. Во все времена люди мечтали о свободе, но минимум знаний мешал ее реализовать. Осознание необходимости происходит за счет информации; чем ее больше и чем она качественнее, тем свободнее становится человек, во всяком случае - и это главное - в выборе поступков. Информационное общество делает прорыв к свободе человека» [Еляков 2001, 85].

Однако здесь воспроизводится позиция некоторой абсолютизации возникшей информационной реальности - объяснение из нее самой ее свойств и особенностей. В этом проявляется обший недостаток в современных исследованиях этой темы: отсутствие основания для проработки связей современности с прошльм. Но эта связь существует в кумулятивных свойствах формы всеобщности субъекта: ее прошлые объективации не исчезают, а сохраняются в виде традиций, культуры, символических и семантических пространств и др.

Действительно, информационный субъект соединяет информацию и деятельность: информация превращается в источник и ресурс современного производства. Но этот субъект должен развернуть и представить как свойства современной личности, так и более ранние свои проявления - всеобщую моральную позицию в обществе, а также оставшиеся нераскрытыми ресурсы мифа. Это значит, что современное информационное пространство, которое раскрывается не только как свойства системы, но и всеобщности субъекта, само по себе еще не завершено: здесь должны выявиться, кроме информационно-технологических, и другие свойства самого общества, в целом выражающие необходимые для общества и личности современные формы гуманизма и социокультурного экзистенциального пространства самого общества. Поэтому свобода личности в ее информационном аспекте оказывается незавершенной: она должна обогатиться пространством культуры, духовности, общественной морали, в совокупности которых более точно может определиться и сама информационная реальность. Именно культурная компонента, а не только информационно-технологическая, должна стать «осью» и ведущим условием современной глобализации.

Итак, информационное пространство как объективация всеобщности субъекта - это проекция не только современной общественной системы, но и исторических трансформаций этого субъекта. Именно поэтому данное пространство можно рассматривать как становление, а не как самодостаточную и завершенную автономную сферу. И только в этом аспекте оно приобретает статус предмета философского и научного исследования.

\section{ПРИМЕЧАНИЯ}

${ }^{1}$ Например, христианство, как духовно-символически и социокультурно выраженное состояние такого субъекта, символически и искаженно воспринимаемого верующими как проявление Бога, сформировало принцип служения Богу, стремление к нему как смысл и основную задачу в жизни верующих.

2 «Снимает»- не значит устраняет: это в принципе невозможно. Но переводит в разряд условий, в которых развертывается новая субъектная организация общества - информационная.

\section{СПИСОК ЛИТЕРАТУРЫ}

Бузский 2002 - Бузский М.П. Субъектная основа бытия и регулирования общества. Волгоград: Изд-во ВолГУ, 2002.

Гадамер 1988 - Гадамер Х.Г. Истина и метод. М.: Прогресс, 1988.

Гегель 1992 - Гегель Г.В. Феноменология духа. Предисловие. СПб.: Наука, 1992.

Гуревич 1972 - Гуревич А.Я. Категории средневековой культуры. М.: Искусство, 1972.

Еляков 2001 - Еляков А. Современное информационное общество // Высшее образование в России. 2001. № 4. С. 77-85.

Игнатов, Пименова 2007 - Игнатов В.С., Пименова Д.В. Информационное пространство // Общественные науки. Социология. 2007. № 3. C. $3-10$.

Кастельс 2000 - Кастельс М. Информационная эра: экономика, общество и культура. М.: Изд-во ГУ ВШЭ, 2000.

Леви-Стросс 1983 - Леви-Стросс К. Структурная антропология. М.: Прогресс, 1983. 


\section{ФИЛОСОФИЯ}

Лосев 1964 - Лосев А.Ф. Мифология // Философская энциклопедия. В 5 т. Т. 3. М.: Совэнциклопедия, 1964. С. 457-467.

Ненашев 2008 - Ненашев А.И. Информационное пространство современного общества: коммуникационный аспект: автореф. дис. ... канд. филос. наук: 09.00.11. Саратов, 2008.

Тоффлер 2001 - Тоффлер Э. Шок будущего. М.: ACT, 2001.

\section{REFERENCES}

Buzskij M.P., 2002. Subjective basis and regulation of society. Volgograd, Izd-vo VolGU.

Gadamer X.G., 1988. Truth and Method. Moscow, Progress Publ.

Gegel G.V., 1992. Phenomenolegy of Spirit. Saint Petersburg, Nauka Publ.
Gurevitch A.J., 1972. Kategories of the Middle Age Culture. Moscow, Iskusstvo Publ.

Eljakov A., 2001. Modern informative Society. Vyssheje Obrazovanije v Rossiji, no. 4, pp. 77-85.

Ignatov B.S., Pimenova D.V., 2007. Information Space. Obshchestvjennyje nauki. Sociologija, no. 3, pp. 3-10.

Kastels M., 2000. Information economic, Society and Culture. Moscow, Izd-vo GU VSHE.

Levi-Stross K., 1983. Structural Antropology. Moscow, Progress Publ.

Losev A.F., 1964. Miphology. Philosophskaja Encyklopedija. In 5 vols. Vol. 3. Moscow, Sovencyklpedija.

Nenashev A.I., 2008. Information Space of modern Society: Communication Aspect. Abstract of the dissertation of the candidate of philosophical sciences. Saratov, 2008.

Toffler A., 2001. Future Shock. Moscow, AST Publ.

\section{Information about the Author}

Marat P. Buzskiy, Doctor of Sciences (Philosophy), Professor, Department of Philosophy, Volgograd State University, Prosp. Universitetsky, 100, 400062 Volgograd, Russian Federation, metamarat1@yandex.ru, socphil@volsu.ru,https://orcid.org/0000-0001-9785-0834

\section{Информация об авторе}

Марат Павлович Бузский, доктор философских наук, профессор кафедры философии, Волгоградский государственный университет, просп. Университетский, 100, 400062 г. Волгоград, Российская Федерация, metamarat1@yandex.ru, socphil@volsu.ru, https://orcid.org/0000-0001-9785-0834 